\title{
The size effect of rebars, on the structural integrity of reinforced concrete structures, which are exposed to corrosive environments.
}

\author{
Argyro Drakakaki ${ }^{*}, \mathbf{1}$, Charis Apostolopoulos ${ }^{2}$ \\ ${ }^{1}$ Mechanical Engineer, PhD Candidate University of Patras, Greece \\ ${ }^{2}$ Civil Engineer, Ass. Professor University of Patras, Greece
}

\begin{abstract}
The goal of the present study is to mention the importance of underestimation of the corrosion damage developed in critical load bearing areas, on the column bases, where formation of plastic hinges is attended, mainly during strong seismic events (Figure 1). In such cases, plastic hinges are expected to absorb the seismic energy, owed to seismic vibration. However, chloride induced corrosion is responsible for significant degradation of concrete infrastructures located in coastal areas. Forecasting the life expectancy of such structures, in corrosive environments, is a challenge in engineering, given the fact that existing internal, external, as well as subcutaneous defects, in combination with the aggressive environmental factors, may be responsible for the development of subcutaneous damage on steel reinforcement [1], which may diminish the tolerance of the critical regions of the structures. Moreover, it is widely known that penetration of chloride ions into reinforced concrete varies according to its porosity and its permeability, however, the major factor for corrosion initiation is the threshold of chloride concentration, which strongly depends on the exposed surface area of steel. In the present experimental study, the variation of corrosion damage, on bare specimens, was evaluated and correlated with the geometry of the exposed surface of steel in corrosion [2]. Finally, a correlation between short bare specimens and the "injured" areas of the long embedded specimens is estimated as well.
\end{abstract}

\section{Introduction}

Safety of structures is generally related to the expected service life, according to established standards and methods. As it has been stated in the CEB-FIP Model Code (1990), "Concrete structures shall be designed, constructed and operated in such a way that, under the expected environmental influences, they maintain their safety, serviceability and acceptable appearance during an explicit or implicit period of time without requiring unforeseen high costs for maintenance and repair" [1]. Consequently, a major step of the durability design, is to analyse the environmental actions and to identify the relevant degradation mechanisms. Hence, it is widely known that during the life of a reinforced concrete structure there are plenty of mechanisms, which can affect the behavior of the structure, both in serviceability and ultimate limit states [2]. All seismic events, existing internal and external defects and corrosion of steel reinforcement, owed to chloride attack, belong to the important influential factors [3].

\footnotetext{
${ }^{1}$ Argyro Drakakaki: drakakaki@upatras.gr
} 
Structures located in marine environments, or structures exposed to de-icing salts in winter from adjacent roads, are vulnerable to chloride-induced corrosion [4]. Precisely, corrosion starts when the chloride content on steel reinforcement reaches a critical threshold, which depends on several parameters including electrochemical potential of the reinforcement, the presence of oxygen, and the conditions of saturation [5]. Temperature and relative humidity constitute affecting factors of corrosion rate as well [6]. Once the concentrated chloride ions break down the passive film around the reinforcement, corrosion starts in the presence of moisture and oxygen. Of course, corrosion progress is also encouraged by existing internal and external defects, the synergy of which results in corrosion paths creation [7]. This process results in formation of expansive corrosion products (rust) around the reinforcement. The volume of corrosion products is about four to six times larger than that of normal steel [8]. The quantity of corrosion products has also been related to the risk of corrosion-induced cracking of the concrete cover [9].

Considering the main effects of corrosion on steel reinforcement, reduction of the effective cross-sectional area of the bars, strength loss and reduction of the bond strength between concrete and bars are recorded, as a result of the increased volume and the rust products of the bars. Moreover, corrosion results in reduced elongation capacity of the bars, as a result of the concentration of plastic deformations at sections of corrosion pits, which greatly affects the displacement capacity of existing buildings. Additionally, the existence of internal voids and defects encourages the premature embrittlement of steel, reducing the available energy stock of the material. Hence, it is known that the displacement capacity is as important as strength, particularly for the buildings that are designed to exhibit ductile behavior during earthquakes [10]. Precisely, according to modern standards, the seismic design of a building is based on its capacity design and the ductility requirements. Additionally, seismic design takes into account the inevitable inelastic behavior of the structures, developing under strong seismic events, resulting to various failure mechanisms.

In reinforced concrete structures located in splash and tidal zones, corrosion occurs on both main reinforcement and the stirrups. Corrosion phenomenon, as well as pitting and existence of defects, contributes to the dramatic reduction of plastic deformation and therefore diminishes not only the energy reserves, but also the expectations for the development of plastic hinges in the corroded regions of the structures, especially under intense seismic events. The situation gets worse when the surfaces that are exposed to the aggressive conditions are short, since higher chloride concentration has been regarded. In such cases, plastic hinges record limited range and reliability.

\section{Experimental Procedure}

For the purpose of simulating natural corrosion in coastal areas, ribbed bars $1 \mathrm{~m}$ long and nominal diameters of $12 \mathrm{~mm}$ were delivered. Five series of specimens were prepared and exposed to corrosion. Two of the sets were $60 \mathrm{~mm}$ long and only $50 \mathrm{~mm}$ were exposed to the corrosive environment and the rest three sets were $500 \mathrm{~mm}$ long and only $250 \mathrm{~mm}$ were exposed to corrosion. The rest part was covered by wax. One of the three long sets of specimens was embedded.

The steel bars embedded in concrete were put in cylindrical plastic tubes (used as concrete moulds), with an internal diameter of $32 \mathrm{~mm}$ and total height of $480 \mathrm{~mm}$. The concrete C16/20 class which was used, was prepared with CEM II cement type and content mix with a water/cement ratio (W/C) of 0,6 [12]. The concrete class $\mathrm{C} 16 / 20$ and coverage of $10 \mathrm{~mm}$ was chosen for two reasons: Firstly, to get faster the desired corrosion results and secondly to simulate the majority of the building stock of Mediterranean countries, for the construction of which, for many years, the same concrete class $(\mathrm{C} 16 / 20)$ was used. Each set, of either short or long specimens, included at least 3 exposure periods. Three specimens were prepared for each exposure case (Table 1). 
Table 1. Number of the corrosion tests performed for the goals of the present study

\begin{tabular}{|c|c|c|c|c|c|c|c|}
\hline $\begin{array}{c}\text { Total } \\
\text { length } \\
(\mathbf{m m})\end{array}$ & $\begin{array}{c}\text { Length of } \\
\text { exposure } \\
\text { area(mm) }\end{array}$ & $\begin{array}{c}\text { Nominal } \\
\text { Diameter } \\
(\mathbf{m m})\end{array}$ & $\begin{array}{c}\text { Bare/ } \\
\text { Embedded }\end{array}$ & $\begin{array}{c}\text { Wet/ } \\
\text { cyclic } \\
\text { cor. } \\
\text { regime }\end{array}$ & $\begin{array}{c}\text { Current } \\
\text { Density } \\
(\mathbf{m A} / \mathbf{c m})\end{array}$ & $\begin{array}{c}\text { Exposure } \\
\text { periods }\end{array}$ & $\begin{array}{c}\text { Number } \\
\text { of } \\
\text { corrosion } \\
\text { tests }\end{array}$ \\
\hline 60 & 50 & 12 & Bare & Cyclic & 0.5 & 6 & 18 \\
\hline 60 & 50 & 12 & Bare & Cyclic & 1 & 5 & 15 \\
\hline 500 & 250 & 12 & Bare & Cyclic & 0.5 & 4 & 12 \\
\hline 500 & 250 & 12 & Bare & Cyclic & 1 & 4 & 12 \\
\hline 500 & 250 & 12 & Embedded & Cyclic & 0.5 & 3 & 9 \\
\hline \multicolumn{7}{|l}{ Total number of corrosion tests } \\
\hline
\end{tabular}

Finally, in order to examine further corrosion damage, special attention was paid to the pitting factor. Pitting measurements were taken with the use of an optical microscope. More than 40 measurements were taken on the surface of each specimen. The mean values of their geometrical characteristics were estimated.

\section{Accelerated Corrosion Process}

Impressed current technique is one of the methods used for accelerated laboratory corrosion (Fig. 1). This technique is in accordance with ASTM standards, although all the individual parameters needed, to create a standard corrosive environment, have not been determined yet. One advantage over other accelerated techniques is the ability to control the rate of corrosion, which usually varies due to changes in the resistivity, oxygen concentration, and temperature [13]. The scientific justification for accelerating corrosion using an impressed current is strong, dramatically reducing the initiation period required for depassivation from years to days and fixing the desired rate of corrosion without compromising the reality of the corrosion products formed [14]. A severe exposure environment of wetting/drying (chloride ponding) was used in the present study. Such a testing regime simulates the chloride exposures of marine structures under splash and tidal zones [15].

Additionally, it should be clarified that the specimens were fully immersed in the chloride solution, during the "wet" process. Full immersion of the specimens can guarantee constant conditions and consequently results of high quality and accuracy, given that repeatability is feasible, since laboratory conditions (humidity, temperature, local conditions) cannot affect the test conditions.

According to the existing literature, the value of the current density that arises due to natural steel corrosion is often between 0.1 and $10 \mu \mathrm{A} / \mathrm{cm} 2$ and occasionally reaches 100 $\mu \mathrm{A} / \mathrm{cm} 2$ [16-18]. However, given the fact that higher current densities are demanded for the execution of accelerated corrosion tests, for the goals of the present study current densities equal to $0.5 \mathrm{~mA} / \mathrm{cm}^{2}$ and $1 \mathrm{~mA} / \mathrm{cm}^{2}$ were imposed.

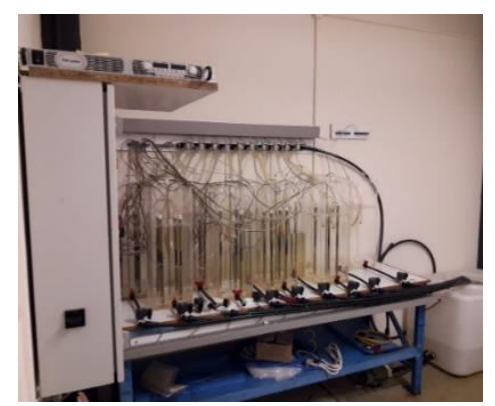


Fig. 1. Electrochemical corrosion system

\section{Results and Discussion}

Corrosion of steel reinforcement in splash and tidal zones contributes to the dramatic reduction of plastic deformation and therefore diminishes the expectations for the development of plastic hinges in the corroded regions of the structures, especially under intense seismic events. However, it should be noted that unexpected intense earthquakes in combination with the non-uniformity of corrosion development on the steel reinforcement at different zones- may trigger the formation of plastic hinges at non-expected regions of the RC elements as well [11]. Nevertheless, seismic design of the RC structures is mainly based on the assumption of the plastic hinges occurring at the two ends of the elements (Fig. 2, 3).

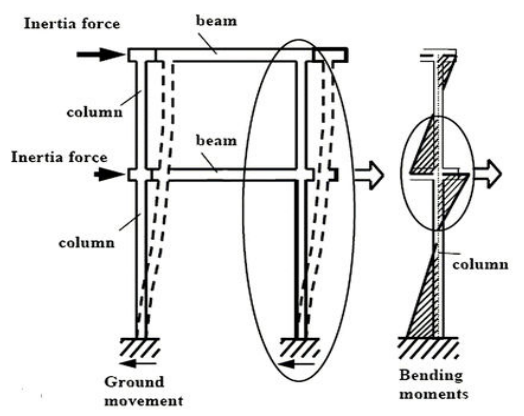

Fig.2. A frame structure under horizontal loads

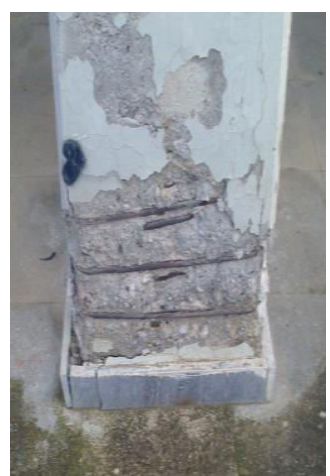

Fig. 3. View of a degraded base of a column, exposed to corrosive environment

In an effort to define the reasons that lead to such phenomena, the internal structure of steel bars was examined. Chemical analyses took place, indicating that not all steel bar classes have the same chemical composition. More specifically, the presence of chemical compounds of $\mathrm{MnS}$ and $\mathrm{FeS}$ or $(\mathrm{Mn}, \mathrm{Fe}) \mathrm{S}$ as components of steel has an influence on the microstructure of the material. From the viewpoint of fracture mechanics, non-metallic inclusions are equivalent to small defects or cracks that can generate stresses within the surrounding matrix $[19,20]$. The impact of this behavior of sulfides, as stress concentrators, 
depends on their size, position and shape, but also on their ability to bond with the matrix material [20]. Additionally, the existence of chemical sulfide compounds that are generated in steel at the stage of production, greatly affect the behaviour of the material against corrosion. Precisely, recent studies [21] have proved that among two different steel bar categories, the one with the lower $\mathrm{S}$ content -which means and lower sulphide contentdemonstrates better corrosion resistance. This is because, as it has been shown, MnS inclusions adversely affect the nature of passive film resulting to accelerated corrosion and pit formation [22]. Investigation of the size effect of the inclusions on the level of stress concentration reveals a critical size of the inclusion where the stress concentration does not increase with the growth of the inclusion for a given applied load and boundary conditions. However, during the violent loading, recycles may cause coalescences of critical importance for the steel, due to their proximity, forcing a multiple cracking phenomenon [7]. In addition, voids present a great corrosion risk as well, when they are partially filled with pore solution [23]. The synergy of existing internal and external defects results in corrosion paths creation (Fig. 4).

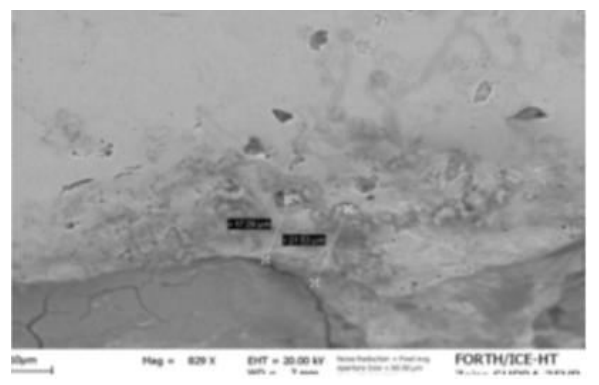

Fig. 4. Formation of corrosion paths

Of course, corrosion mechanism is activated easier in aggressive conditions. Harsh coastal environment has detrimental results on the mechanical performance of the reinforced concrete structures, although the consequences of corrosion damage are not included in the existing regulations, concerning reinforced concrete structures. More accurately, corrosion has more significant impact on ductility loss of RC components than flexural capacity loss [24-25].

Another parameter, examined in the present study, affecting the structural integrity of the $\mathrm{RC}$ structures, is the length of the surface which is exposed to corrosion. Initially, four sets of specimens (two short and two long) were exposed to artificial coastal conditions and corrosion damage was evaluated. Tables 2-5 present the mass loss rates recorded for each case, as well as the geometrical characteristics of the developed pits.

Table 2: The mass loss values and the pitting characteristics that were recorded for the short specimens $\Phi 12$, that were corroded under $0.5 \mathrm{~mA} / \mathrm{cm} 2$ current density.

\begin{tabular}{|c|c|c|c|c|c|c|c|c|}
\hline $\begin{array}{c}\text { Diameter } \\
(\mathbf{m m})\end{array}$ & Time (h) & $\begin{array}{c}\text { Current } \\
\text { (A) }\end{array}$ & $\begin{array}{c}\text { Current } \\
\text { Density } \\
(\mathrm{mA} / \mathrm{cm} 2)\end{array}$ & $\begin{array}{c}\text { Mass } \\
\text { loss (\%) }\end{array}$ & $\begin{array}{c}\text { mean } \\
\text { pit } \\
\text { depth } \\
(\mu \mathrm{m})\end{array}$ & $\begin{array}{c}\max . \\
\text { pit } \\
\text { depth } \\
(\mu \mathrm{m})\end{array}$ & $\begin{array}{c}\text { mean } \\
\text { pit } \\
\text { area } \\
(\mathrm{mm} 2)\end{array}$ & $\begin{array}{c}\text { max. } \\
\text { pit } \\
\text { area } \\
(\mathbf{m m 2})\end{array}$ \\
\hline 12 & 15 & 0.009 & 0.5 & 0.49 & 89 & 163 & 0.32 & 1.00 \\
\hline 12 & 24 & 0.009 & 0.5 & 0.67 & 96 & 128 & 0.35 & 2.15 \\
\hline 12 & 40 & 0.009 & 0.5 & 1.18 & 112 & 168 & 0.40 & 1.32 \\
\hline 12 & 72 & 0.009 & 0.5 & 1.71 & 116 & 192 & 0.17 & 0.67 \\
\hline
\end{tabular}

Table 3: The mass loss values and the pitting characteristics that were recorded for the long- bare specimens $\Phi 12$, that were corroded under $0.5 \mathrm{~mA} / \mathrm{cm} 2$ current density. 


\begin{tabular}{|c|c|c|c|c|c|c|c|c|}
\hline $\begin{array}{c}\text { Diameter } \\
(\mathbf{m m})\end{array}$ & Time (h) & $\begin{array}{l}\text { Current } \\
\text { (A) }\end{array}$ & $\begin{array}{c}\text { Current } \\
\text { density } \\
(\mathrm{mA} / \mathrm{cm} 2)\end{array}$ & $\begin{array}{c}\text { Mass } \\
\text { loss (\%) }\end{array}$ & $\begin{array}{c}\text { mean } \\
\text { pit } \\
\text { depth } \\
(\mu \mathrm{m})\end{array}$ & $\begin{array}{c}\text { max. } \\
\text { pit } \\
\text { depth } \\
(\mu \mathrm{m})\end{array}$ & $\begin{array}{c}\text { mean } \\
\text { pit } \\
\text { area } \\
(\mathrm{mm} 2)\end{array}$ & $\begin{array}{c}\text { max. } \\
\text { pit } \\
\text { area } \\
(\mathrm{mm} 2)\end{array}$ \\
\hline 12 & 40 & 0.05 & 0.5 & 0.80 & 45 & 86 & 0.05 & 0,71 \\
\hline 12 & 104 & 0.05 & 0.5 & 1.50 & 65 & 148 & 0.08 & 0,36 \\
\hline 12 & 160 & 0.05 & 0.5 & 1.93 & 74 & 185 & 0.12 & 0,71 \\
\hline 12 & 200 & 0.05 & 0.5 & 2.53 & 76 & 160 & 0.13 & 0,54 \\
\hline
\end{tabular}

Table 4: The mass loss values and the pitting characteristics that were recorded for the short specimens $\Phi 12$, that were corroded under $1 \mathrm{~mA} / \mathrm{cm} 2$ current density.

\begin{tabular}{|c|c|c|c|c|c|c|c|c|}
\hline $\begin{array}{c}\text { Diameter } \\
(\mathrm{mm})\end{array}$ & Time (h) & $\begin{array}{l}\text { Current } \\
\text { (A) }\end{array}$ & $\begin{array}{c}\text { Current } \\
\text { Density } \\
(\mathrm{mA} / \mathrm{cm} 2)\end{array}$ & $\begin{array}{c}\text { Mass } \\
\text { loss (\%) }\end{array}$ & $\begin{array}{c}\text { mean } \\
\text { pit } \\
\text { depth } \\
(\mu \mathrm{m})\end{array}$ & $\begin{array}{c}\text { max. } \\
\text { pit } \\
\text { depth } \\
(\mu \mathrm{m})\end{array}$ & $\begin{array}{c}\text { mean } \\
\text { pit } \\
\text { area } \\
(\mathrm{mm} 2)\end{array}$ & $\begin{array}{c}\text { max. } \\
\text { pit area } \\
(\mathrm{mm} 2)\end{array}$ \\
\hline 12 & 5 & 0.019 & 1 & 0.45 & 79 & 144 & 0.164 & 0.322 \\
\hline 12 & 15 & 0.019 & 1 & 0.93 & 97 & 166 & 0.221 & 0.345 \\
\hline 12 & 24 & 0.019 & 1 & 1.40 & 121 & 168 & 0.294 & 0.986 \\
\hline 12 & 40 & 0.019 & 1 & 2.40 & 131 & 200 & 0.481 & 1.299 \\
\hline 12 & 72 & 0.019 & 1 & 3.70 & 137 & 175 & 0.488 & 1.464 \\
\hline
\end{tabular}

Table 5: The mass loss values and the pitting characteristics that were recorded for the long- bare specimens $\Phi 12$, that were corroded under $1 \mathrm{~mA} / \mathrm{cm} 2$ current density.

\begin{tabular}{|c|c|c|c|c|c|c|c|c|}
\hline $\begin{array}{l}\text { Diameter } \\
(\mathrm{mm})\end{array}$ & Time (h) & $\begin{array}{l}\text { Current } \\
\text { (A) }\end{array}$ & $\begin{array}{c}\text { Current } \\
\text { density } \\
(\mathrm{mA} / \mathrm{cm} 2)\end{array}$ & $\begin{array}{l}\text { Mass } \\
\text { loss } \\
(\%)\end{array}$ & $\begin{array}{c}\text { mean } \\
\text { pit } \\
\text { depth } \\
(\mu \mathrm{m})\end{array}$ & $\begin{array}{c}\text { max. } \\
\text { pit } \\
\text { depth } \\
(\mu \mathrm{m})\end{array}$ & $\begin{array}{c}\text { mean } \\
\text { pit } \\
\text { area } \\
(\mathrm{mm} 2)\end{array}$ & $\begin{array}{c}\text { max. } \\
\text { pit } \\
\text { area } \\
(\mathrm{mm} 2)\end{array}$ \\
\hline 12 & 36 & 0.094 & 1 & 1.06 & 82 & 110 & 0.18 & 0.26 \\
\hline 12 & 72 & 0.094 & 1 & 1.53 & 95 & 120 & 0.25 & 0.42 \\
\hline 12 & 108 & 0.094 & 1 & 2.02 & 105 & 160 & 0.37 & 0.63 \\
\hline 12 & 144 & 0.094 & 1 & 2.58 & 118 & 300 & 0.60 & 2.11 \\
\hline
\end{tabular}

Additionally, in Diagrams 1 and 2 is graphically presented the comparison mass loss, of the short and the long sets of specimens corroded under the same conditions, as far as mass loss percentages are concerned.

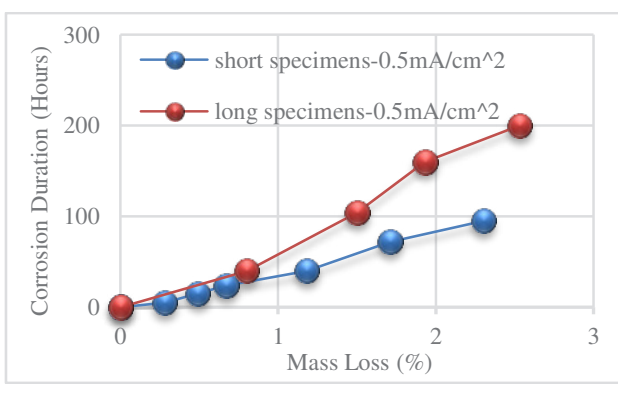

Diagram 1: Graphical presentation and comparison of two series of specimens (short and long), of the same diameter $\Phi 12$, that were corroded under $0.5 \mathrm{~mA} / \mathrm{cm}^{2}$ current density.

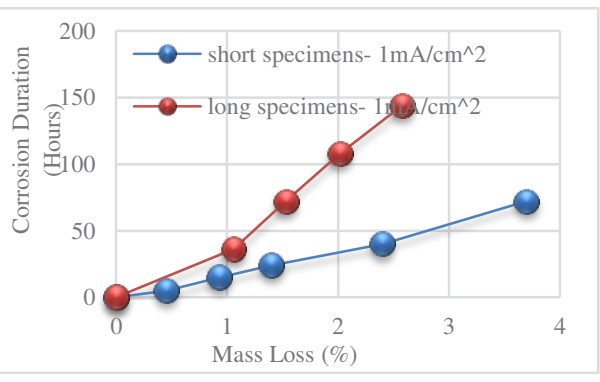

Diagram 2: Graphical presentation and comparison of two series of specimens (short and long), of the same diameter $\Phi 12$, that were corroded under $1 \mathrm{~mA} / \mathrm{cm}^{2}$ current density. 
Comparing short and long series of specimens, of the same diameter, for the same corrosion duration, it seems that short samples record higher mass loss percentages and more intense pitting. Precisely, mass loss rate of the short- $0.5 \mathrm{~mA} / \mathrm{cm} 2$ specimens, after 40 hours exposure to corrosion, is $38 \%$ higher than the mass loss rate of the long bare specimens (that have five times higher exposed length than the length of short samples). At the same time, mean pit depth of the short specimens was more than two times higher than the value recorded for long specimens. Similar findings were reported for the specimens corroded under $1 \mathrm{~mA} / \mathrm{cm} 2$ current density.

According to existing studies, pitting corrosion initiates preferentially during the dry cycle, after a critical chloride concentration.

According to Angst U.M. [26] chloride concentration at the steel surface needed to initiate corrosion decreases with increasing length of the reinforced concrete beams exposed to chlorides. To describe the possibilities of concentration of a critical percentage of chlorides in long specimens against short specimens, Angst [26] used in his study equation (1).

$$
p_{L}=1-\left(1-p_{M}\right)^{k}
$$

Where: $\mathrm{p}_{\mathrm{L}}$ and $\mathrm{p}_{\mathrm{M}}$ are the corrosion possibilities of a long and a short specimen respectively and $\mathrm{k}$ is the ratio of the big length to the shorter one.

It is suggested that this size effect can be explained by inhomogeneities found at the steel surface. Consequently, increasing the specimen size will thus increase the probability for the presence of conditions favoring corrosion initiation at lower chloride concentrations. These may include zones of particularly corrosion-susceptible steel metallurgy (for example, accumulations of inclusions) or areas where the concrete adjacent to the steel offers low corrosion protection [26].

In order to further investigate the phenomenon in reinforced concrete cases, a set of embedded specimens was prepared and corroded under the same conditions, as the bare specimens. Current density equal to $0.5 \mathrm{~mA} / \mathrm{cm}^{2}$ was then imposed. Mass loss percentages and pitting characteristics of the embedded specimens, are presented in Table 6.

Table 6: The mass loss values and the pitting characteristics that were recorded for the longembedded specimens $\Phi 12$, that were corroded under $0.5 \mathrm{~mA} / \mathrm{cm} 2$ current density.

\begin{tabular}{|c|c|c|c|c|c|c|c|c|}
\hline $\begin{array}{l}\text { Diameter( } \\
\mathrm{mm})\end{array}$ & $\begin{array}{c}\text { Time } \\
\text { (h) }\end{array}$ & $\begin{array}{c}\text { Current } \\
\text { (A) }\end{array}$ & $\begin{array}{c}\text { Current } \\
\text { density } \\
(\mathrm{mA} / \mathrm{cm} 2)\end{array}$ & $\begin{array}{c}\text { Mass } \\
\text { loss } \\
(\%)\end{array}$ & $\begin{array}{c}\text { mean } \\
\text { pit } \\
\text { depth } \\
(\mu \mathrm{m})\end{array}$ & $\begin{array}{c}\text { max. } \\
\text { pit } \\
\text { depth } \\
(\mu \mathrm{m})\end{array}$ & $\begin{array}{c}\text { mean } \\
\text { pit } \\
\text { area } \\
(\mathrm{mm} 2)\end{array}$ & $\begin{array}{c}\text { max. pit area } \\
(\mathbf{m m} 2)\end{array}$ \\
\hline 12 & 40 & 0.05 & 0.5 & 0.53 & 42 & 73 & 0.09 & 0.17 \\
\hline 12 & 80 & 0.05 & 0.5 & 0.58 & 45 & 72 & 0.09 & 0.41 \\
\hline 12 & 200 & 0.05 & 0.5 & 0.64 & 48 & 73 & 0.11 & 0.72 \\
\hline
\end{tabular}

Angst U.M. [26] also mentions that, for steel in concrete, further spatial variability is introduced because of the inhomogeneous nature of the composite material concrete. In concrete, part of the chlorides which penetrate, are combined with the cement phases, which makes the process not dependent only of the transport, but of the proportion of bound chlorides as well [27]. The chloride threshold in concrete is usually presented as a ratio of the total chloride to cement content of concrete (expressed as a weight percentage). Typical values range between 0.2 and $2.5 \%$ by weight of cement [28]. 


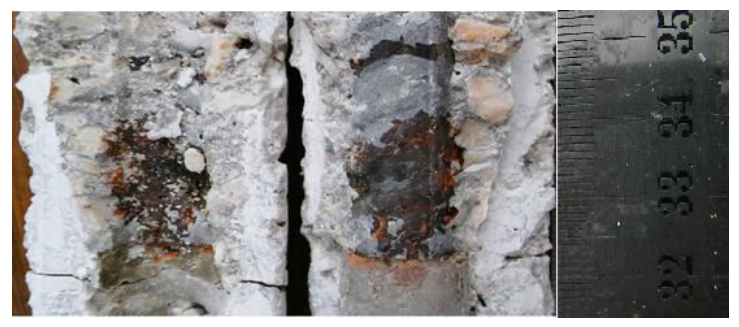

Fig. 5. View of a local corrosion damage on an embedded specimen

After further examination of the corrosion- prone areas, rust products can be noted on individual locations. Specifically, in embedded specimens, rust was accumulated in short areas, 30-50mm long. This fact is similar to the cases of short exposure lengths, in corrosive environment (Figure 5). According to this, damage recorded on long embedded specimens can be paralleled with the corresponding damage described for specimens of short length. This means that embedded specimens operate like short bare specimens at areas where critical chloride concentration has been reached, due to the defective casting of concrete.

In an effort to correlate these findings with real phenomena, many examples come in mind. Severe cracks at the edges of reinforced concrete columns or lack of ductility, given the inability of proper development and energy loading of the plastic hinges, occurring after intense earthquakes, and presenting short exposed surface, are just a few of them.

\section{Conclusions}

The main conclusions of the present study are the following:

- Due to corrosion occurrence, the coalescence of internal and external defects, as well as pitting phenomenon recorded on steel reinforcement, may result in high stress concentration and possibly to degradation of its mechanical performance.

- Long- bare steel bar specimens recorded milder corrosion damage (mass loss and pit depth) than short-bare specimens, for the same exposure conditions, and this is because in short specimens there is demand for higher chloride concentration for the corrosion initiation

- Given the fact that corrosion effect is initially concentrated in small areas in longembedded specimens, their corrosion to behavior can be simulated with the corresponding behavior of short- bare specimens.

- All the previously mentioned phenomena may constitute deteriorating factors for the mechanical performance of critical regions of RC structures, such as plastic hinges. Consequently, there is a great demand for further investigation.

In any case, in order to make a reliable prediction concerning corrosion of reinforcing steel in concrete, further research studies should take place on the following issues so as to obtain knowledge, which can be useful for real-existing structures as well:

(i) quantifying the size effect on real systems and surface conditions

(ii) combination of materials science and structural engineering (mechanical behavior)

(iii) role of the steel-concrete interface in corrosion initiation.

\section{References}

1. T.Siemes, C. Edvardsen, Cowi, Durabiliy of Building Materials and Components, 8, 1343-1356, 1999.

2. D. Byrne, J. Goggins, Key Engineering Materials, 569, 382-389, 2013 
3. C. Suwito, Y. Xi, Structure and Infrastructure Engineering, 4, 177-192, 2008

4. M.M. Kashani, L.N. Lowes, A.J. Crewe, N.A. Alexander, 75, 113-125, 2014

5. E. Camnasio, PhD Thesis, University of Milan, 2013

6. K.R. Gowers,S.G. Millard, Proceedings of the Institution of Civil Engineers d Structures and Buildings, 134, 2, 1999

7. C.Apostolopoulos, A. Drakakaki, A. Apostolopoulos, T. Matikas,G. Kodzhaspirov, Materials Physics and Mechanics, 30, 1-19, 2017

8. Y. Liu, PhD Dissertation, Virginia Polytechnic Institute and State University, 1996

9. P. Schiessl, M. Raupach, ACI Materials Journal, 94, 1, 1997

10. P. Inci, C. Gosku, A. Ilki, N. Kumbasar, Journal of Performance of Constructed Facilities, 27, 6, 2013

11. W. Yuan, A. Guo, H. Li, Soil Dynamics and Earthquake Engineering, 102, 112-123, 2017

12. C.A.Apostolopoulos, V.P. Pasialis, Construction and Building Materials, 22, 23252334, 2008.

13. A. Shamsad, Arabian Journal for Science and Engineering, 34, 95-104, 2009

14. S.A. Austin, R. Lyons, M.J. Ing, Corrosion, 60, 203-212, 2004

15. M. Quanmin, V. Sreejith, P.A. Nanukuttan, M. Basheer, Y. Bai, C. Yang, Materials and Structures, 49, 3663-3677, 2016.

16. C. Alonso, C. Andrade, J. Rodriguez, J.M. Diez, Materials \& Structures, 31, 435-441, 1998

17. C. Andrade, C. Alonso, Construction \& Building Materials, 15, 141-145, 2001

18. G. Malumbela, P. Moyo, M. Alexander, Journal of the South African Institution of Journal Engineering, 54, 78-85, 2012

19. R. Kiessling, Encyclopedia of Materials: Science and Technology, 6278-6283, 2001

20. C.Temmel, N.G. Ingesten, B. Karlsson, Metallurgical and Materials Transactions A, 37, 2995-3007, 2006

21. Alk. Apostolopoulos, A. Drakakaki, G. Konstantopoulos, T. Matikas, Humanities \& Science University Journal, 22-32, 2015.

22.A.A. Negheimish, A. Alhozaimy, R.R. Hussain, R. Al-Zaid, J.K. Singh, D.D.N. Singh// NACE International, 70, 1,2014.

23. G.K. Glass, N.R. Buenfield, Prog. Struct. Engng. Mater, 2, 448-458, 2000

24. X. Li, Y.S Zhao, H.L. Ly, Construction and Building Materials, 101, 902-917, 2015

25. A.Meda, S. Mostosi, Z. Rinaldi, P. Riva, Engineering Structures, 76, 112-123, 2014

26. U.M.Angst, B.Elsener, Applied Sciences and Engineering, 3, 2017.

27. C.Andrade, 3rd Workshop on Testing and Modeling the Chloride Ingress into Concrete, Madrid, Spain, 2002.

28. G.K. Glass,N.R. Buenfeld, Corrosion Science, 39, 5, 1997 